\title{
PERANCANGAN MOTION COMIC BERTEMA KULINER CIREBON MENGGUNAKAN KARAKTER TOPENG CIREBON DALAM INSTAGRAM
}

\author{
Vicky Septian Rachman ${ }^{* 1}$, Hansen Kamarga ${ }^{2}$ \\ Institut Teknologi dan Bisnis Kalbis \\ Correspondence author: Vicky Septian Rachman, Vicky.rachman@kalbis.ac.id, Jakarta, Indonesia
}

\begin{abstract}
Abstrak. Cirebon merupakan salah satu kota yang memiliki budaya-tradisi yang khas, salah satunya dalam bidang kuliner. Beberapa kuliner seperti Empal Gentong, Sate Kalong dan Mie Koclok merupakan makanan yang memiliki ciri khas dari kota Cirebon. kuliner khas kota Cirebon perlu dilestarikan agar dapat bersaing dengan kuliner modern yang kini semakin diminati. Penelitian ini bertujuan untuk merancang motion comic kuliner Cirebon yang ditargetkan kepada milenial. Penelitian menerapkan metode kualitatif dengan pengumpulan data melalui studi pustaka, wawancara dan observasi. Perancangan motion comic terdiri dari studi cerita, studi karakter, storyline, storyboard, sketsa, digitalisasi, pewarnaan digital dan motioning. Motion comic yang dirancang diperankan oleh karakter visual topeng Cirebon bergaya visual chibi sebagai pendukung cerita untuk memberikan informasi secara menarik bagi target audiens yang dipilih. Elemenelemen motion comic ditata sedemikian rupa sesuai format media Instagram yang populer di kalangan milenial. Perancangan dimaksudkan sebagai pemacu agar milenial dapat mengenali kebudayaan dan mampu berkarya dengan memasukan unsur budaya sebagai identitasnya. Oleh karena itu, perancangan motion comic ini merupakan penggabungan tiga unsur yaitu DesainBudaya-Teknologi.
\end{abstract}

Kata Kunci: motion comic, kuliner Cirebon, topeng Cirebon, budaya Indonesia.

\begin{abstract}
Cirebon is a city that has unique cultures, one of them is the cuisine. Some cuisine such as Empal Gentong, Sate Kalong and Mie Koclok are foods that have the characteristics of the city of Cirebon. Cirebon cuisine need to be preserved in order to compete with modern cuisine that are now increasingly in demand. This research aims to design Cirebon cuisine motion comics that are targeted at millennials. This research applies qualitative methods by collecting data through literature studies, interviews and observations. Motion comic design consists of story study, character study, storyline, storyboarding, sketching, digitization, digital coloring and motioning. A motion comic designed to be played by a visual character based on Topeng Cirebon which has a chibi visual style to support the story to provide interesting information for the target audience. The motion comic elements are laid out in such a way as to the Instagram media format which is popular among millennials. The design is intended as a spur so that millennials can recognize the culture and be able to create a work by incorporate cultural elements as their identity. Therefore, the design of this motion comic is a combination of three elements, namely Design-Culture-Technology.
\end{abstract}

Keywords: motion comic, Cirebon cuisine, topeng Cirebon, Indonesian culture. 


\section{Pendahuluan}

Komik merupakan imaji-imaji gambar atau imaji lainnya, yang dijajarkan dalam urutan yang disengaja untuk menyampaikan informasi dan menimbulkan tanggapan estetis pada pembacanya. Akronim cerita bergambar, mengikuti istilah cerpen (cerita pendek) yang sudah terlebih dahulu digunakan, dan konotasinya menjadi lebih bagus, meski terlepas dari masalah tepat tidaknya dari segi kebahasaan atau etimologis katanya (McCloud 1993). Komik dapat diterbitkan dalam berbagai bentuk, mulai dari strip dalam koran, dimuat dalam majalah, hingga berbentuk buku tersendiri. Pada tahun 1996, Will Eisner menerbitkan buku Graphic Storytelling, di mana ia mendefinisikan komik sebagai "tatanan gambar dan balon kata yang berurutan, dalam sebuah buku komik." Sebelumnya, pada tahun 1986, dalam buku Comics and Sequential Art, Eisner mendefinisikan teknis dan struktur komik sebagai sequential art, "susunan gambar dan kata-kata untuk menceritakan sesuatu atau mendramatisasi suatu ide". Para ahli masih belum sependapat mengenai definisi komik. Sebagian diantaranya berpendapat bahwa bentuk cetaknya perlu ditekankan. Yang lain lebih mementingkan kesinambungan gambar dan teks. Sebagian lain lebih menekankan sifat kesinambungannya (sequential). Definisi komik sendiri sangat supel karena itu berkembanglah berbagai istilah baru seperti:

- Picture stories - Rodolphe Topffer (1845)

- Pictorial narratives - Frans Masereel and Lynd Ward (1930s)

- Picture novella - dengan nama samaran Drake Waller (1950s).

- Illustories - Charles Biro (1950s)

- Picto-fiction - Bill Gaine (1950s)

- Sequential art (graphic novel) - Will Eisner (1978)

- Nouvelle manga - Frederic Boilet (2001)

Komik selalu memiliki peminatnya tersendiri, hal ini yang membuat komik dapat bertahan keeksisannya hingga kini.

Pada era digital seperti sekarang komik mengalami evolusi. Komik tidak hanya dapat dinikmati melalui buku. Kini komik dapat juga dinikmati melalui perangkat digital seperti televisi, komputer bahkan dengan smartphone. Komikpun tidak lagi hanya berupa gambar kaku yang tidak bergerak. Pada sekitar tahun 2005 Lionsgate perusahaan yang berasal dari Kanada merilis komik bergerak pertamanya dalam bentuk digital yang disebut motion comic. Motion Comic adalah komik/novel grafis dalam format video yang dibuat/diolah melalui proses digital animasi. Tidak seperti komik/novel grafis biasa, motion comic dapat dinikmati seperti halnya saat menyaksikan tayangan video animasi dari televisi, komputer maupun perangkat audio visual lainnya. Sebuah cerita teks yang dijadikan animasi lewat komputer, sehingga audiens tidak perlu membacanya karena sudah menggunakan narasi dan ilustrasi visual. Proses berbicaranya tidak hanya menggunakan balon kata tapi menggunkan voice actor (pengisi suara) sebagai tokoh yang dimainkannya (Karamoy, Ardianto, and Erandaru 2013). Pada dasarnya motion comic merupakan animasi-animasi yang sering kita lihat pada umumnya, perbedaanya hanya dalm motion comic animasi yang digunakan merupakan animasi sederhana dengan minim gerakan.

Audio visual, merupakan suatu media penyampaian pesan yang sangat efesien yang mudah diterima oleh audiencenya. Audio visual sudah menjadi bagian dari keseharian kita seperti dalam televisi, komputer, maupun gadget lainnya. Dalam audio visual terdapat berbagai program yang ditawarkan seperti berita, video musik, film, bahkan motion comic. Dalam berbagai audio visual terdapat pesan seperti pada film contohnya, hampir seluruh film terdapat pesan moral walaupun secara tidak langsung, hal ini juga berlaku dengan motion comic, dengan dukungan audio visual motion comic juga dapat memberikan pesan moral pada audience-nya.

"Budaya sebagai identitas", seperti yang dikatakan komikus Toni Masdiono merupakan kesepakatan para seniman komik dimana asal-usul komik Indonesia tidak terlalu jelas asal- 
muasalnya. Dengan adanya budaya makan komik tersebut mempunyai ciri khas sekaligus menjadi identitas dimana komik tersebut dibuatnya. Pada penelitian ini, motion comic dirancang dengan memasukan unsur budaya kota Cirebon baik dari segi cerita maupun dari karakter visualnya.

Kisah asal-usul Cirebon dapat ditemukan dalam historiografi tradisional yang ditulis dalam bentuk manuskrip (naskah) yang ditulis pada abad ke-18 dan ke-19. Naskah-naskah tersebut dapat dijadikan pegangan sementara sehingga sumber primer ditemukan. diantara naskahnaskah yang memuat sejarah awal Cirebon adalah Carita Purwaka Caruban Nagari, Babad Cirebon, Sajarah Kasultanan Cirebon, Babad Walangsungsang, dan lain-lain. Yang paling menarik adalah naskah Carita Purwaka Caruban Nagari, ditulis pada tahun 1720 oleh Pangeran Aria Cirebon, Putera Sultan Kasepuhan yang pernah diangkat sebagai perantara para Bupati Priangan dengan VOC antara tahun 1706-1723.

Dalam naskah itu pula disebutkan bahwa asal mula kata "Cirebon" adalah "sarumban", lalu mengalami perubahan pengucapan menjadi "Caruban". Kata ini mengalami proses perubahan lagi menjadi "Carbon", berubah menjadi kata "Cerbon", dan akhirnya menjadi kata "Cirebon". Menurut sumber ini, para wali menyebut Carbon sebagai "Pusat Jagat", negeri yang dianggap terletak ditengah-tengah Pulau Jawa. Masyarakat setempat menyebutnya "Negeri Gede". Kata ini kemudian berubah pengucapannya menjadi "Garage" dan berproses lagi menjadi "Grage".

Menurut P.S. Sulendraningrat, penanggung jawab sejarah Cirebon, munculnya istilah tersebut dikaitkan dengan pembuatan terasi yang dilakukan oleh Pangeran Cakrabumi alias Cakrabuana. Kata "Cirebon" berdasarkan kiratabasa dalam Bahasa Sunda berasal dari "Ci" artinya "air" dan "rebon" yaitu "udang kecil" sebagai bahan pembuat terasi. Perkiraan ini dihubungkan dengan kenyataan bahwa dari dahulu hingga sekarang, Cirebon merupakan penghasil udang dan terasi yang berkualitas baik (Santri 2008).

Pada bagian lain dapat menyelami teknik membatik, yaitu teknik mencetak atau melukis kain dengan cara menutup sebagian dari kain dengan malam atau perekat yang dibuat dari beras dan bahan lain sudah sangat tua umurnya dan seperti juga patung dari batu atau kayu, pada asalnya merupakan sebagian dari upacara tradisional. Tetapi kain lekas punah dan karena itu kini tidak ada lagi peninggalannya. Dalam konteks Cirebon, banyak terdapat gaya-gaya dengan pola-pola yang berani, berbentuk liong, singa, gajah, mega mendung, wadas, tumbuh-tumbuhan menjalar serta ayam jago yang berkokok. Kebanyakan motif ini merupakan lambang yang dipuja, yang menunjukan kekuatan jantan dan keberanian, malah kadang-kadang keagresifan, petunjuk tentang suatu bangsa yang ingin memperkenalkan kehadirannya setelah begitu lama diterlantarkan oleh dunia luar (Natadiningrat).

Selain sejarah dan berbagai kebudayaannya yang menarik, kota Cirebon juga memiliki budaya yang menjadi daya tarik untuk dapat menarik pengunjung baik dari dalam maupun luar negeri, budaya tersebut adalah kuliner khas kota Cirebon. Berbagai macam kuliner asal kota Cirebon sudah dikenal akan cita rasanya yang khas diantaranya seperti Empal Gentong, Sate Kalong, Mie Koclok dan sebagainya. Pelestarian kuliner khas Cirebon menjadi perlu karena banyaknya mall dan cafe yang menawarkan kuliner modern di kota Cirebon. Dengan pelestarian kuliner asal Cirebon diharapkan tidak akan punah dan tetap dapat bersaing dengan kuliner modern yang cukup diminati pada saat ini (Suparno, Ilhamsyah, and Nurusholih 2015).

Tidak semua orang tahu akan kekayaan yang terdapat di Cirebon termasuk kuliner khas asal Cirebon, namun dengan membuat komik yang mengangkat kebudayaan kota Cirebon maka akan memberikan pengetahuan lebih untuk para pembacanya terutama dalam kuliner khas Cirebon. Tidak hanya komik konvensional, pada penelitian ini komik yang dihasilkan adalah komik yang bergerak atau yang lebih sering dikenal dengan sebutan motion comic dengan tujuan dapat menarik perhatian dan lebih mudah dipahami. Perancangan motion comic yang dibuat nantinya terdapat karakter visual topeng Cirebon dari yang sebelumnya sudah dibuat. 
Perancangan motion comic ini ditargetkan kepada generasi milenial. Generasi milenial merupakan generasi praktis atau dalam bahasa modernnya disebut generasi zaman now. Generasi milenial lahir pada rentang tahun 1980-2000an, atau dengan kata lain generasi Angkatan 80-an ke atas. Generasi ini lahir dari bias kategorisasi yang terpengaruh demografik masyarakat barat. Dengan adanya perkembangan internet pada era digital kini sangat mudah bagi dunia untuk terpengaruh apapun yang terjadi di dunia barat (Sari 2019). Perancangan dimaksudkan sebagai pemacu agar milenial dapat mengenali kebudayaan dan mampu berkarya dengan memasukan unsur budaya sebagai identitasnya. Dengan menargetkan milenial sebagai audience maka diperlukan media yang dapat menjangkau milenial untuk dapat mengakses motion comic yang akan dibuat. Media yang digunakan untuk mempublisnya adalah media sosial digital atau lebih spesifiknya menggunakan media aplikasi Instagram.

Dapat dijabarkan perancangan motion comic ini merupakan penggabungan tiga unsur yaitu Desain-Budaya-Teknologi yang dapat dipersempit lagi menjadi Seni Ilustrasi-TradisiTeknologi Digital hal tersebut dapat lebih mengkerucut lagi agar perancangan tidak melebar luas menjadi Komik Kontemporer-Kuliner Cirebon-Media Sosial. Maka perancangan motion comic lebih dikonsentrasikan pada Komik kontemporer, budaya Cirebon dan media sosial sebagai media publikasi untuk milenial.

\section{Metode}

Penelitian ini dilakukan dengan metode kualitatif dengan pengumpulan data dalam penelitian ini sebagian besar dilakukan melalui studi pustaka dan observasi, adapun studi pustaka meliputi tentang pendalaman komik, motion comic maupun studi pustaka tentang kebudayaan Cirebon. Dalam perancangan motion comic dibagi ke dalam beberapa tahapan yaitu studi pustaka tentang motion comic, analisis data dari kumpulan referensi, observasi dan analisis data kuliner khas Cirebon, analisis hasil pengolahan data, membuat narasi, mengumpulkan aset grafis, motioning dan publikasi sosial media (proses di mana hasil motion comic dipublikasikan ke sosial media untuk dapat diakses)

\section{Hasil dan Pembahasan}

\section{Perancangan Motion Comic Dengan Tema Kuliner Cirebon}

Kuliner selalu menjadi daya tarik tersendiri pada suatu daerah yang menjadi ciri khas bahkan tradisi pada suatu tempat. Tidak jarang wisatawan yang berburu kuliner hingga ke berbagai tempat untuk merasakan langsung bagaimana makanan khas pada suatu daerah dengan cita rasa yang unik. Pada jurnal Kuliner sebagai Identitas Keindonesiaan yang ditulis oleh Fadly Rahman mengatakan perkembangan makanan di Indonesia sebenarnya adalah perwujudan dari fussion antar unsur citarasa asing dengan citarasa Indonesia. Hal ini karena terdapat pengaruh dari berbagai negara sehingga menghasilkan cita rasa yang kaya (Rahman 2018). Pemilihan tema kuliner Cirebon pada perancangan motion comic bukan tanpa alasan, kuliner ciri khas pada suatu tempat juga dapat menjadi awal bagaimana seseorang ingin dapat lebih mengenali asal daerah dari kuliner tersebut. Setiap kuliner yang mempunyai ciri khas pasti mempunyai sejarah tersendiri bagaimana kuliner tersebut bisa tercipta. Banyak faktor yang mempengaruhi terciptanya kuliner ciri khas suatu daerah yang mungkin tidak kita ketahui bagaimana bisa terjadi. Dengan dimulai dengan kuliner maka dapat mengenal asal daerahnya dan mengetahui sejarahnya, hal ini juga dapat disederhanakan menjadi kuliner-daerah-sejarah. 
McCloud (2000) menjelaskan bahwa komik dalam bentuk digital (Multimedia) menawarkan lebih kesan visual dengan penambahan dari segi kesan bunyi, pergerakan dan interaktiviti. McCloud juga menjelaskan dengan menggabungkan ciri-ciri komik seperti gaya, genre, balon dialog, struktur panel dan sebagainya dengan interaktif media, suara watak dan suara latar, bunyi seolah-olah membaca balon dialog, sedikit elemen animasi dan pembaca boleh memilih plot kesukaan menjadikan komik tersebut hidup didalam persekitaran maya (McCloud 2000). McCloud memaparkan komik bermaksud "Sequential Art" dalam arti kata lain komik adalah gambar atau imej yang mewujudkan jalan cerita (McCloud 1993).

Dalam buku Pekan Komik dan Animasi Nasional 98 mengatakan komik sebagai cermin budaya. Sebagai produk budaya komik-pun bisa menjadi cermin dari state of art perkembangan budaya suatu masyarakat. Sampai tahun 60an komik-komik yang disenangi pembaca adalah tentang kisah kepahlawanan, kejuangan, kepeloporan, pionior dan ketegaran menghadapi tantangan. tetapi hampir semua dibangun atas dasar impian atau idealisasi tentang masa lampau. Belum ada komik-komik tentang impian atau gambaran masa depan. Ditinjau dari perspektif waktu mungkin budaya Indonesia belum memiliki acuan impian tentang masa depan (Sedyawati et al. 1998).

Dalam perancangan motion comic dengan tema kulier Cirebon langkah pertama yang diperlukan adalah mencari kisah, sejarah atau apapun yang diperlukan untuk menggali informasi pada kuliner asal Cirebon. Informasi didapatkan dari hasil studi pustaka, wawancara, internet dan observasi. Informasi yang didapatkan lalu dicatat lalu dikembangkan menjadi sebuah cerita yang nantinya digunakan dalam perancangan motion comic.

\section{Perancangan Motion Comic Dengan Tema Kuliner Cirebon}

Terhitung dari awal penelitian, peneliti sudah mendapat beberapa data yang didapat melalui studi pustaka, wawancara, internet dan observasi. Adapun data yang didapat adalah susunan proses untuk membuat motion comic. Komponen-komponen yang terdapat pada motion comic tidak jauh berbeda dengan komik konvensional, komponen pada motion comic terdiri dari gambar yang mengilustrasikan karakter dan tempat kejadian, materi atau cerita, dan bahasa sebagai alat mengomunikasikan sebuah cerita kepada audience-nya (Pratiwi, Nurketi, and Putri 2020). Perkembangan motion comic di Indonesia sendiri masih terbatas, tidak terdapatnya buku maupun kurangnya pembahasan tentang motion comic, namun hal ini dapat menjadi peluang untuk dapat memperluas bidang seni yang disebut "Pop Culture" agar dapat dikenal oleh khalayak khususnya di Indonesia. Terdapat beberapa proses dalam perancangan motion comic yang notabennya menggunakan perangkat elektronik seperti smartphone, laptop, komputer dan Ipad. Seperti yang diungkapkan oleh Indiria Maharsi, motion comic menjadi semacam alternatif baru bagi pengembangan komik secara khusus. Terlebih lagi komik ini pada saat sekarang banyak digemari oleh para pembaca karena kemudahan akses dan kebaruan cara presentasinya (Maharsi 2018). Untuk mendapatkan data yang valid, penelti juga merancang motion comic yang dibuat dengan tema topeng Cirebon dengan menggunakan karakter topeng Cirebon. Dalam proses merancang motion comic ini peneliti mendapatkan fakta-fakta diantaranya adalah :

1. Studi cerita

Pada proses ini merupakan inti dalam perancangan motion comic. Pada proses ini ideide dikumpulkan, dicatat dan dibuat menjadi cerita yang digunakan dalam motion comic. Pada perancangan motion comic kali ini cerita yang digunakan dibatasi sekitar kuliner Cirebon agar cerita yang dibuat tidak keluar dari tema yang sudah ditentukan. 


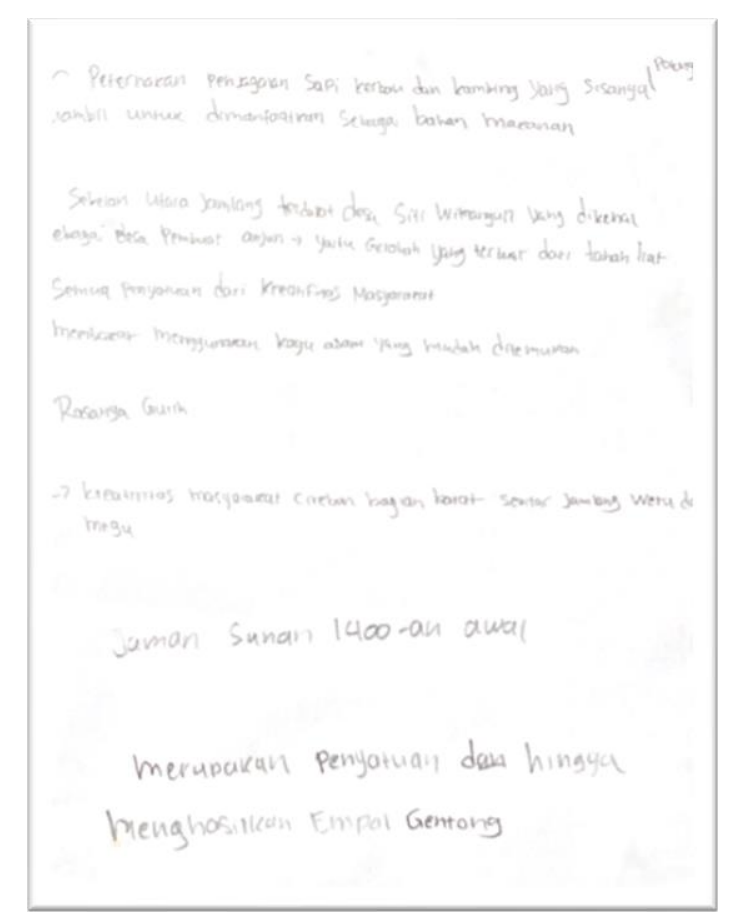

Gambar 1 Studi cerita Topeng Cirebon

2. Studi karakter (proses pencarian elemen-elemen pada karakter).

Untuk mendapatkan karakter yang sesuai dengan alur cerita yang diinginkan, maka karakter yang digunakan harus melalui tahap studi karakter. Tahap ini memungkinkan seorang komikus mengeksplorasi beberapa bagian tubuh, gestur serta ekspresi untuk mendapatkan karakter yang sesuai. Untuk mendapatkan karakterpun memerlukan tahapan yang bila di persingkat dimulai dari konsep, sketsa, hingga ke finalisasi warna. Pada perancangan motion comic dengan tema kuliner Cirebon karakter yang digunakan adalah karakter topeng Cirebon. Karakter ini merupakan hasil penelitian sebelumnya yang sekiranya tepat untuk diplikasikan pada motion comic yang dirancang. Dalam pembuatan karakter topeng Cirebon, karakter yang digunakan menggunakan gaya chibi. Penggambaran karakter chibi memiliki rasio antara kepala sampai tubuh antara 1: 1 dan 4: 1. Jadi dalam penggambaran chibi kepala tidak selalu lebih besar dari pada tubuh, tetapi juga memiliki potensi jadi jauh lebih besar. Selain itu, fitur pada wajah biasanya dilebih-lebihkan dan dikumpulkan ke bagian tengah wajah (Musnur and Faiz 2019).

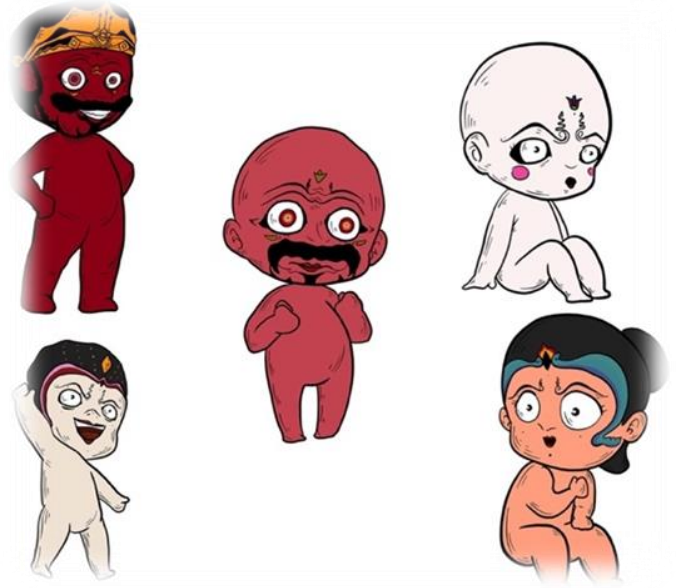

Gambar 2 Karakter Topeng Cirebon 
3. Storyline (cerita yang diolah dan siap divisualkan).

Cerita yang sudah didapatkan kemudian dikembangkan dan diurutkan sehingga dapat terstruktur untuk mempermudah dalam menerjemahkan cerita menjadi gambar. Agar lebih terlihat rapih peneliti mengetik hasil cerita yang telah didapatkan.

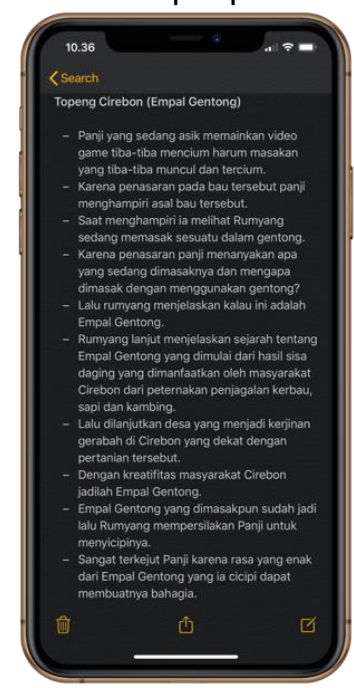

Gambar 3 Storyline (Empal Gentong)

4. Storyboard (proses sketsa guna mendapatkan gambaran dari storyline).

Proses ini merupakan lanjutan setelah storyline didapatkan. Pada proses storyboard hasil storyline yang didapatkan divisualisasikan dalam bentuk gambar. Pada proses ini gambaran-gambaran kasar sudah mulai terbentuk dan terlihat dasarnya.

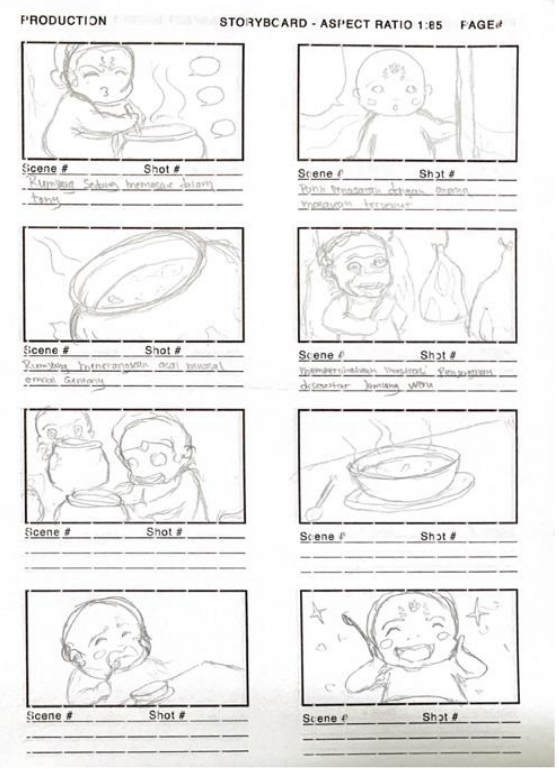

Gambar 4 Storyboard (Empal Gentong)

5. Sketsa Komik (proses dasar mengambar dan pembagian panel).

Sketsa mulai dibentuk menggunakan bidang dengan ukuran yang disesuaikan. Sketsa merupakan pondasi dalam pembentukan sebuah gambar tegas. Pada proses ini perencanaan visual pada sebuah frame dibuat sebelum nantinya dibuat dalam bentuk outline. 


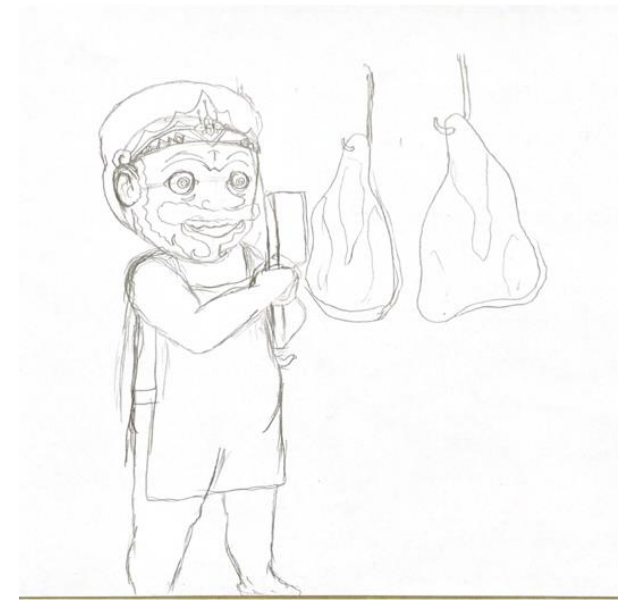

Gambar 5 Sketsa komik

6. Digitalisasi (proses perancangan sketsa kemudian dilanjutkan pada komputer agar mudah diaplikasikan pada beberapa media).

Pada proses ini, outline dibuat berdasarkan sketsa yang sebelumnya sudah dirancang. Pada perancangan motion comic tentu format yang digunakan dalam bentuk digital, maka outline dibuat dengan menggunakan program dengan format digital.

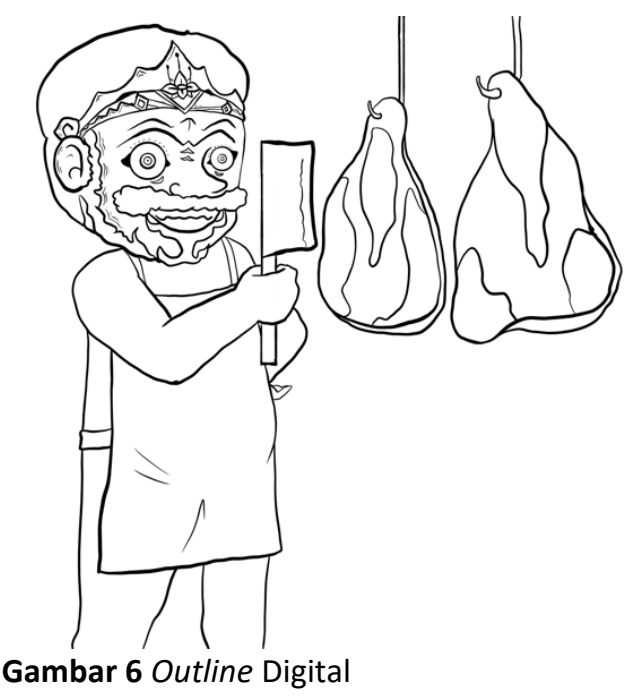

7. Pewarnaan Digital (proses pewarnaan digital menggunakan perangkat elektronik).

Pewarnaan juga tidak lepas dengan penggunaan program digital. Pada proses ini dibutuhkan kepekaan warna agar warna yang digunakan dapat terlihat harmonis. Dengan bantuan skema warna yang tepat maka palet warna yang digunakan dapat terlihat menarik dan konsisten. 


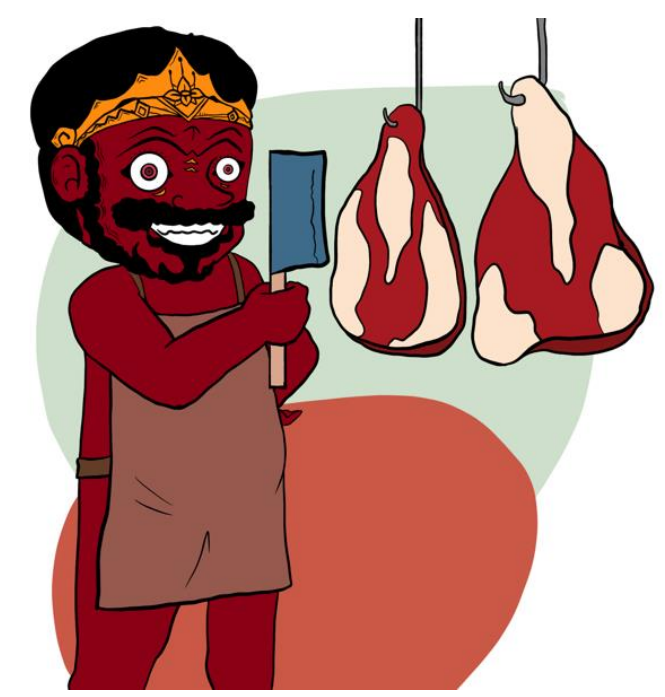

Gambar B Pewarnaan Digital

8. Motioning (proses terakhir yang menjadi titik berat motion comic adalah menggerakan bagian-bagian tertentu dalam gambar komik menggunakan software pendukung).

Memasuki proses inti dalam perancangan motion comic, pada tahap ini semua dikerjakan menggunakan program komputer. Terdapat beberapa software yang dapat digunakan untuk membuat motion comic, sebagian besar data yang didapatkan oleh penulis pada proses motioning menggunakan software Adobe After Effect yang diyakini memiliki berbagai fitur pendukung untuk membuat motion comic. Proses ini seringkali disebut dengan motion graphic. Menurut Rahmi dan Iman motion graphic merupakan sebuah grafis yang menggunakan video atau animasi untuk menciptakan ilusi gerak ataupun transformasi sebuah visual. Graphic design telah berubah dari static publishing dengan memanfaatkan teknologi komunikasi termasuk film, animasi, media interaktif, dan environmental design (Wardhani and Sudjudi 2014).

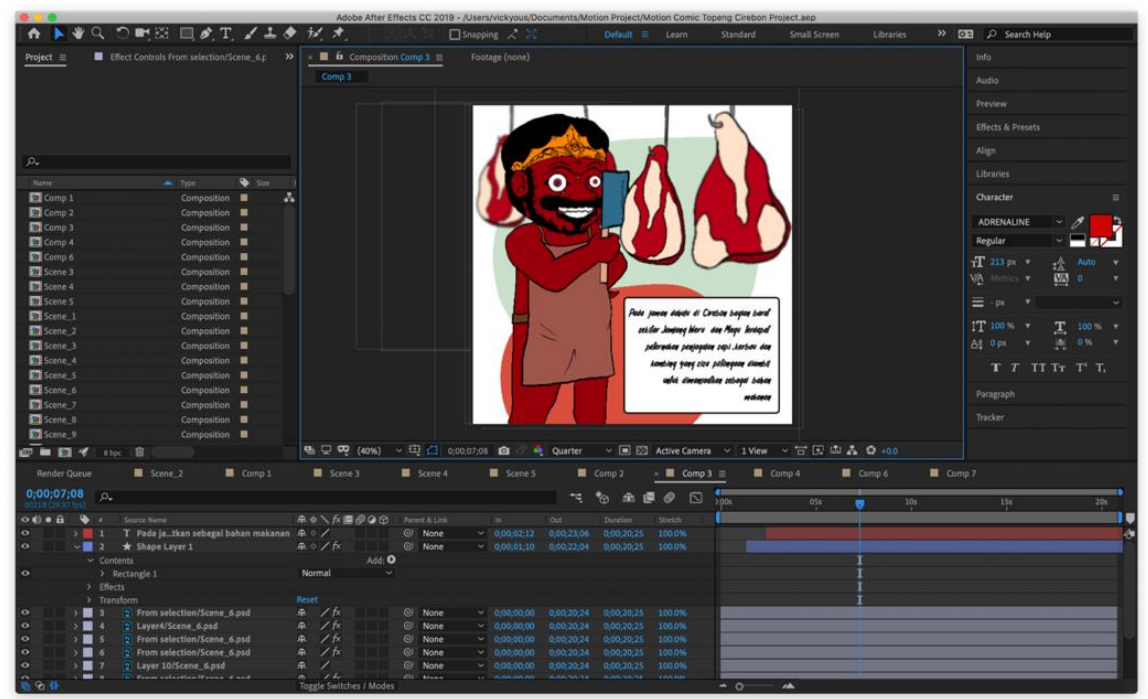

Gambar 8 Motioning

\section{Elemen pada Motion Comic}

Pada perancangan motion comic terdapat beberapa elemen penting yang menjadikan karya ini sebagai motion comic. Elemen-elemen ini tersusun menjadi satu-kesatuan hingga menjadikannya visual yang layak untuk dipublikasikan. 


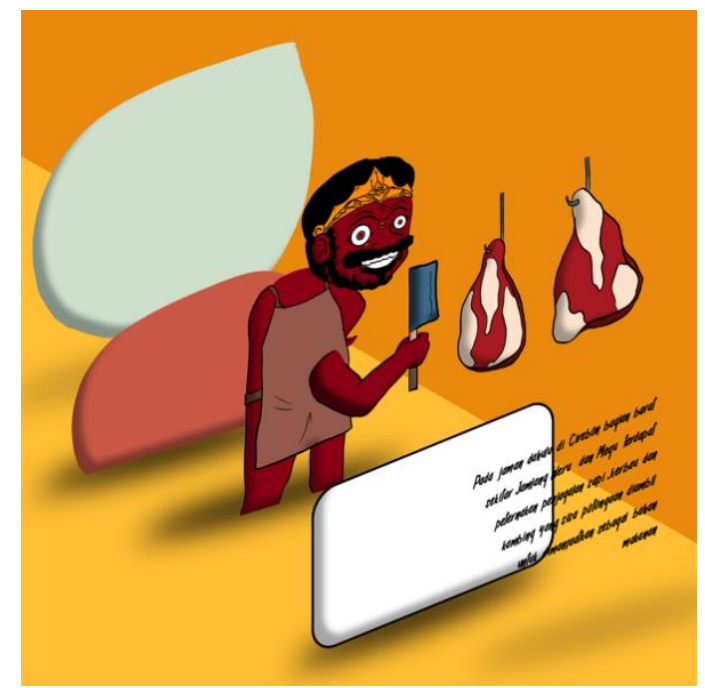

Gambar 9 Elemen visual motion comic

Dalam sebuah unggahan motion comic terdapat elemen-elemen visual yang cukup kompleks hingga menghasilkan gambar yang baik, Adapun elemen-elemen yang terdapat pada sebuah unggahan motion comic sebagai berikut:

1. Visual Object

Pada perancangan motion comic kuliner Cirebon objek visual yang disajikan berupa karakter topeng Cirebin dengan berbagai property pendukungnya. Objek visual yang ditekankan digambar lebih detail dari objek visual yang lainnyan, contohnya seperti visual Empal Gentong yang dibuat lebih detail dari objek lainnya.

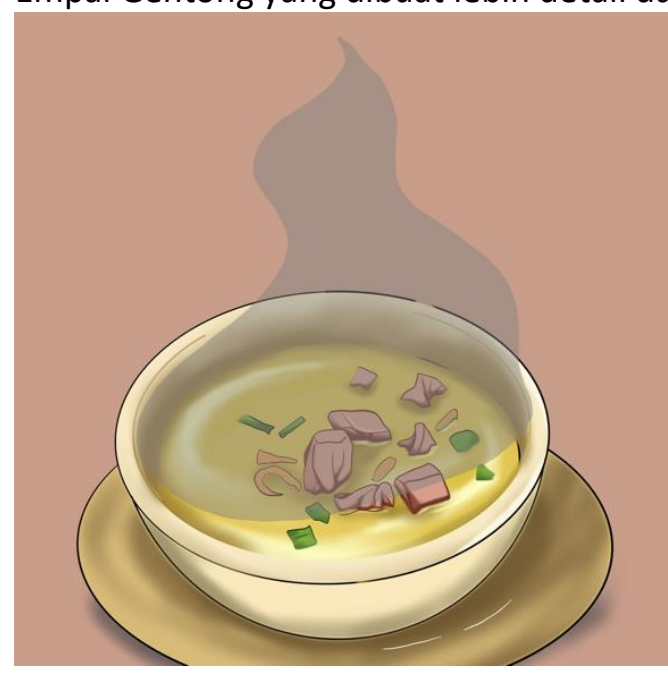

Gambar 10 Visusl Object Empal Gentong

Pada objek yang akan digerakan juga terdapat cara khusus untuk mempermudah motioning yaitu dengan cara memisahkan bagian-bagian tertentu pada objek. 


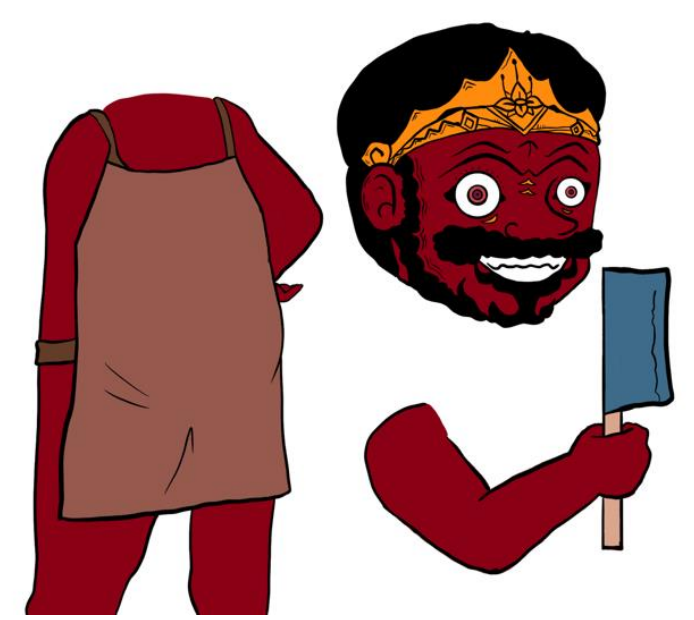

Gambar 11 Visusl Object Character

2. Text

Teks merupakan bagian pendukung untuk menyampaikan maksud selain menggunakan gambar. Teks berhubungan dengan typeface karena dalam menggunakan media digital teks yang digunakan dalam bentuk typeface. Pada motion comic dengan tema topeng Cirebon penggunaan teks menggunakan typeface Adrenaline. Adrenaline merupakan typeface yang relatif sulit dibaca. Bukan tanpa alasan, penggunaan typeface ini memang disesuaikan dengan target audience yaitu milenial. Menurut riset generasi milenial lebih menyukai tantangan daripada generasi sebelumnya. Dengan alasan tersebut maka dipilih font yang lebih sulit dibaca agar penyampaian pada target audience dapat dapat lebih spesifik. Namun penggunaan typeface masih dapat disesuaikan sesuai dengan keadaan tertentu.

\section{$A B C D E F G H I J K L M N O P Q$}

\section{$R S T \cup \vee W \times Y Z$}

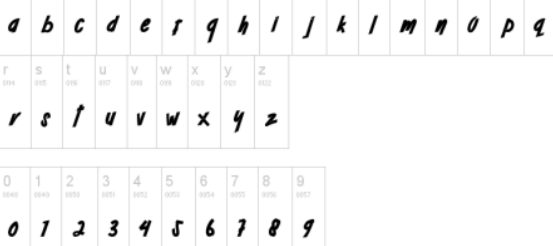

Gambar 12Typeface Adrenaline

3. Bubble Text

Desain bentuk balon kata berguna untuk menunjukkan ekspresi karakter seperti kaget, senang, bingung, dan lain-lain (Adhinata 2013). Balon kata merupakan elemen yang dapat membantu dalam hal membaca teks. Dengan adanya balon teks dapat mamperjelas teks yang disampaikan walaupun ada di depan visual yang cukup rumit. Balon teks juga dapat memperjelas maksud apakah sedang berbicara santai, berteriak atau menyampaikan narasi. Balon teks yang digunakan dalam motion comic kuliner Cirebon cukup sederhana, hal tersebut dimaksudkan agar fokus tetap berada pada objek visual. 


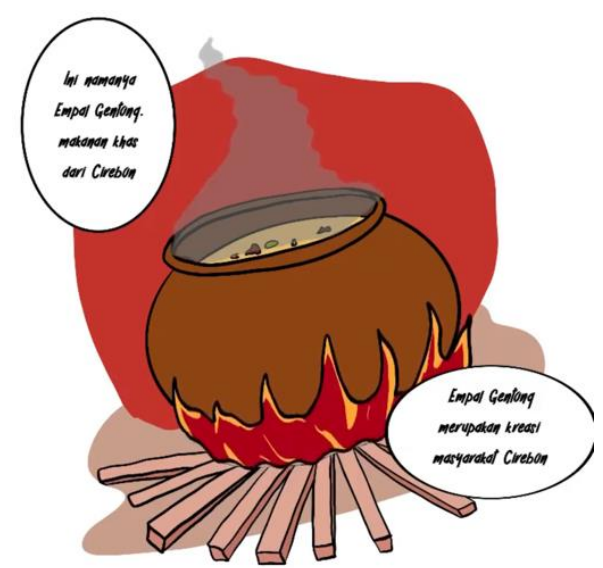

Gambar 13 Bubble Text Motion Comic Kuliner Cirebon

4. Background

Background berupa latar tempat yang akan digunakan di dalam scene motion comic, sementara foreground berupa bagian dari lingkungan sekitar sebagai penambah suasana dalam motion comic (Selvia, Prestiliano, and Prasida 2020). Background atau latar belakang berfungsi untuk memberikan informasi yang terkait dengan tempat. Latar belakang tidak selalu berbentuk lanskap pemandangan tetapi juga dapat berupa blok warna. Pada motion comic kuliner Cirebon latar belakang yang digunakan hanya berupa bidang-bidang warna yang dimaksudkan agar objek visual dapat lebih terlihat menonjol daripada latar belakangnya.

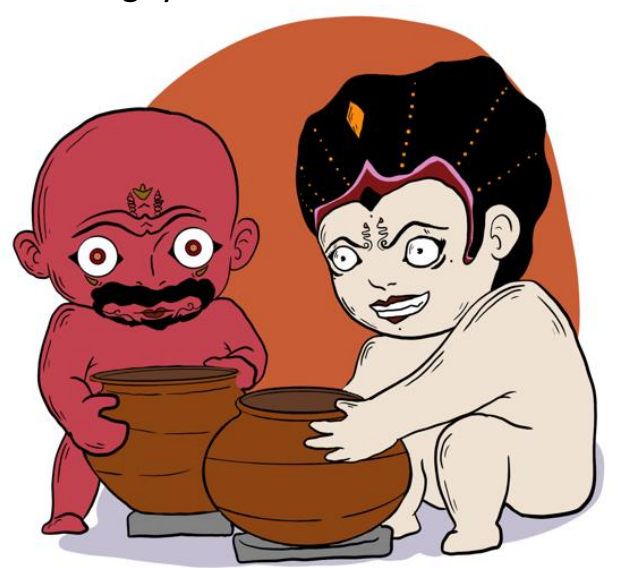

Gambar 14 Background Motion Comic Kuliner Cirebon

\section{Publikasi Motion Comic}

Setelah motion comic selesai dibuat tentunya media publikasi harus dipikirkan. Melanjutkan dari penelitian sebelumnya, media publikasi yang digunakan dalam motion comic dengan tema topeng Cirebon adalah Instagram. Sesuai dengan target audience sebelumnya yaitu milenial, Instagram diyakini dapat mengantarkan informasi pada milenial. Selain menyediakan layanan untuk berbagi gambar, Instagram juga menyediakan layanan untuk berbagi video dalam feed. Durasai yang dapat diunggah dalam feed Instagram dibatasi hanya satu menit, maka dalam perancangan motion comic dengan tema kuliner Cirebon cerita yang digunakan harus selesai dalam jangka satu menit. Untuk memaksimalkan unggahan video dalam Instagram perlu juga memperhatikan ukuran frame video. Seperti yang telah diketahui Instagram memiliki ciri khas frame 1:1 dalam feed, maka frame video mengikuti ukuran menjadi 1:1 dengan ukuran 2048px x 2048px. Video dalam Instagram diawali dengan judul cerita terlebih 
dahulu sebelum masuk dalam ceritanya. Thumbnail yang digunakan untuk unggahan video dalam feed berupa judul, gambar makanan khas Cirebon dan logo kuliner Cirebon untuk dapat menarik pada saat memasuki halaman profil Instagram.

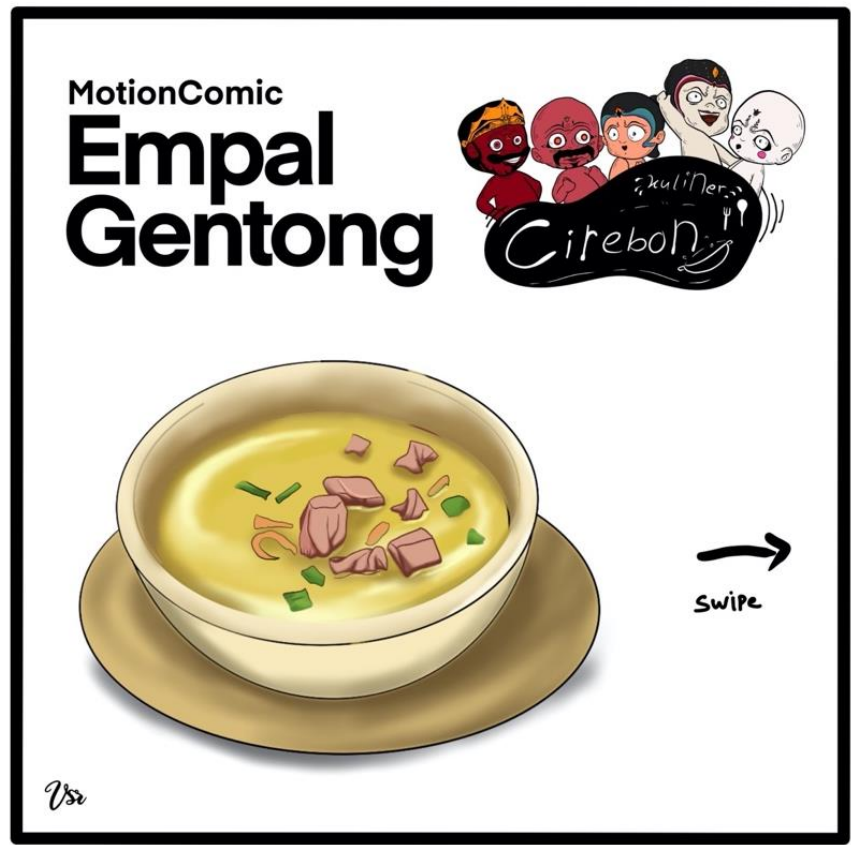

Gambar 15 Judul Motion Comic Kuliner Cirebon

Unggahan pada Instagram dalam bentuk video memiliki daya tarik sendiri, berbeda dengan unggahan dalm bentuk foto, pada postingan berupa video memberikan gambar yang bergerak yang tidak monoton. Dalam satu unggahan motion comic terdapat 10 halaman yang terdiri dari judul dan isi motion comic. Unggahan diberikan caption berupa judul dan penegasan motion comic dengan kolom komentar yang dibuka agar audience dapat memberikan tanggapan pada hasil unggahan. Pada Langkah awal peneliti menggunakan akun Instagram pribadi untuk melihat hasil dan mendapat tanggapan dari audience.
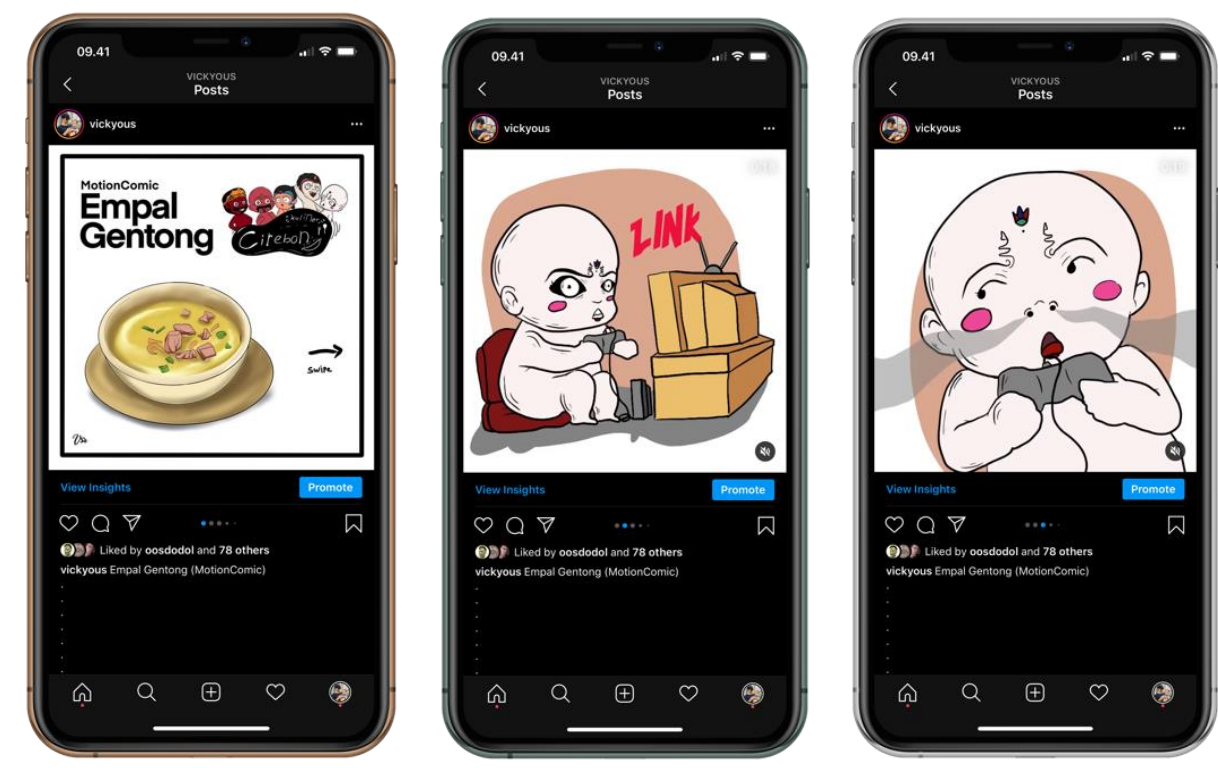

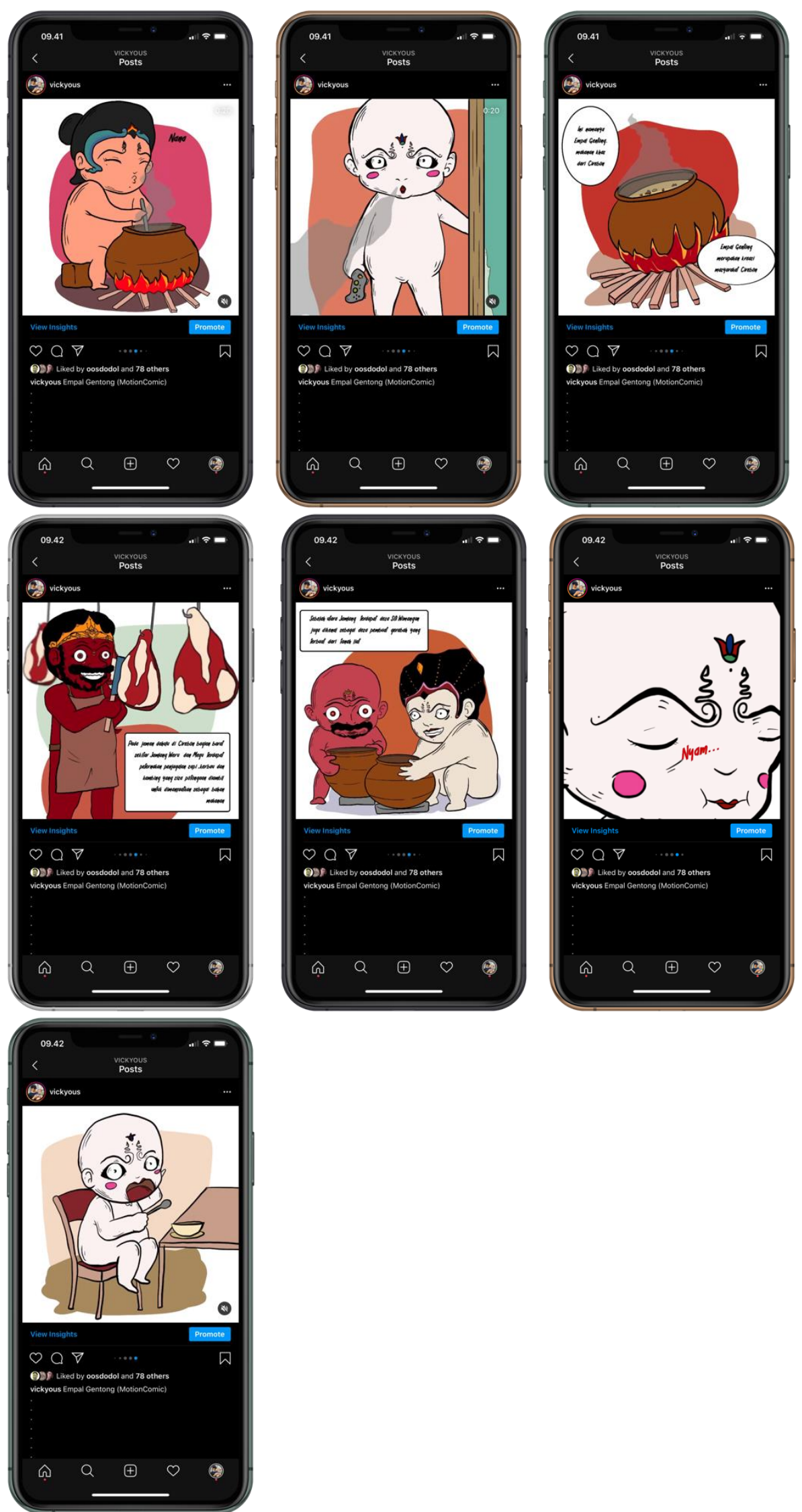

Gambar 16 Tampilan Instagram Motion Comic Kuliner Cirebon 
Pada motion comic yang diunggah oleh akun peneliti didapatkan data yang terlihat dari jumlah like dan kolom comment. Dalam rentang waktu sekitar 15 jam unggahan sudah dilihat oleh 315 pengunjung, mendapatkan 88 like dan 11 comment. Like dan comment didominasi oleh generasi milenial dan generasi Y. Comment yang datang juga beragam, ada yang memberikan saran, menyampaikan kesukaan pada motion comic dan ada yang berminat untuk mempelajarinya.

\section{Simpulan}

Kesimpulan yang dapat diambil dari penelitian ini adalah :

1. Menurut data yang didapatkan perancangan motion comic terdiri dari studi cerita, studi karakter, storyline, storyboard, sketsa, digitalisasi, pewarnaan digital dan motioning. Pada pembuatan motion comic juga ada elemen-elemen yang perlu diketahui untuk mendapatkan kesan komiknya yaitu visual object, text, bubble text dan background. Peranan desainer pada perancangan motion comic hampir dapat mencakup seluruhnya mungkin hanya perancangan musik bila menggunakannya yang tidak dapat dilakukan oleh desainer grafis.

2. Melanjutkan dari penelitian sebelumnya untuk penyapaian atau publikasi komik tersebut melalui media sosial Instagram. Instagram merupakan media sosial yang populer dikalangan milenial sehingga tepat bila publikasi motion comic dilakukan pada media sosial Instagram. Motion comic disesuaikan dengan format Instagram dengan menggunakan 10 halaman feed yang terdiri dari judul pada halaman awalnya dan dilanjutkan dengan susunan motion comic.

3. Hasil penelitian yang dilakukan oleh peneliti dengan mengunggah motion comic melalui akun pribadi sekitar 15 jam mendapatkan hasil 315 pengunjung, 88 like dan 11 comment. Like dan comment didominasi oleh generasi milenial dan generasi $Y$. hal tersebut sudah dapat menyimpulkan bahwa target audience yang dituju sudah sesuai untuk pesan yang disampaikan masih masih belum dapat disampaikan, Sebagian lebih tertarik dengan visual dari motion comic daripada isi ceritanya.

\section{Daftar Pustaka}

Adhinata, Nico. 2013. "Pembuatan Motion Comic Penjelasan Ilmiah Tentang Peristiwa SehariHari Untuk Siswa Smp." Calyptra : Jurnal IImiah Mahasiswa Universitas Surabaya 2 (2): 1-18. http://journal.ubaya.ac.id/index.php/jimus/article/view/749.

Karamoy, Philipus Nicolaus, Deny Tri Ardianto, and Erandaru Erandaru. 2013. "Perancangan Motion Comic Tokoh Pewayangan Bambang Ekalaya." Jurnal DKV Adiwarna 1 (2): 7. http://publication.petra.ac.id/index.php/dkv/article/view/621.

Maharsi, Indiria. 2018. "Penciptaan Motion Comic Wayang Beber Jaka Kembang Kuning." DeKaVe 11 (1): 17-23. https://doi.org/10.24821/dkv.v11i1.2485.

McCloud, Scott. 1993. Understanding Comics: The Invisible Art. New York: Harper Collins Publishers.

---. 2000. Reinventing Comics: The Evolution of an Art Form. New York: Harper Colins Publishers. 
Musnur, Irfandi, and Muhamad Faiz. 2019. "Analisis Penyajian Karakter dan Alur Cerita pada Komik Vulcaman-z." Narada : Jurnal Desain dan Seni 6 (2): 317-338. https://doi.org/10.22441/narada.2019.v6.i2.010.

Natadiningrat, PRA. Arief. "Sejarah Kesenian." Pemerintah Daerah Kota Cirebon. Accessed 4 November 2019. https://www.cirebonkota.go.id/profil/sejarah/sejarah-kesenian.

Pratiwi, Vira, Nunuy Nurketi, and Faradiba Catur Putri. 2020. "Pengembangan Motion Comic Berbasis Kearifan Lokal dalam Berpikir Aljabar di Sekolah Dasar." Vygotsky: Jurnal Pendidikan Matematika dan Matematika 2 (1): 23-32. https://doi.org/10.30736/vj.v2i1.183.

Rahman, Fadly. 2018. "Kuliner sebagai Identitas Keindonesiaan." Jurnal Sejarah (1): 43-63\%V 2. https://doi.org/10.26639/is.v2i1.118. http://jurnal.masyarakatsejarawan.or.id/index.php/js/article/view/118.

Santri, K. 2008. "Sejarah Keraton." Pemerintah Daerah Kota Cirebon. Last Modified 3 April. Accessed 4 November 2019. https://www.cirebonkota.go.id/profil/sejarah/sejarahkeraton.

Sari, Sapta. 2019. "Literasi Media pada Generasi Milenial di Era Digital." Profesional: Jurnal $\begin{array}{llllll}\text { Komunikasi Dan } & \text { Administrasi Publik } 6 & \text { (2): } & \text { 30-42. }\end{array}$ https://doi.org/10.37676/professional.v6i2.943.

Sedyawati, Edy, Rahayu S. Hidayat, Dwi Koendoro, and Wagiono. 1998. Pekan Komik \& Animasi Nasional 98 (6-12 Februari 1998). Direktorat Jenderal Kebudayaan, Departemen Pendidikan dan Kebudayaan Republik Indonesia.

Selvia, Jasson Prestiliano, and T. Arie Setiawan Prasida. 2020. "Perancangan Motion Comic sebagai Media Edukasi tentang Kepedulian terhadap Gangguan Kecemasan Sosial pada Remaja." Intuisi: Jurnal Psikologi IImiah 12 (1): 48-65. https://doi.org/10.15294/intuisi.v12i1.23503.

Suparno, Eva, Ilhamsyah, and Sonson Nurusholih. 2015. "Perancangan Promosi Destinasi Wisata Kuliner Khas Cirebon." eProceedings of Art \& Design 2 (2): 478-485. https://openlibrarypublications.telkomuniversity.ac.id/index.php/artdesign/article/vie w/4106.

Wardhani, Rahmi Kesuma, and Iman Sudjudi. 2014. "Perancangan Video Dokumenter "Autisme"." Visual Communication Design 3 (1). https://www.neliti.com/publications/180546/perancangan-video-dokumenterautisme\#cite. 